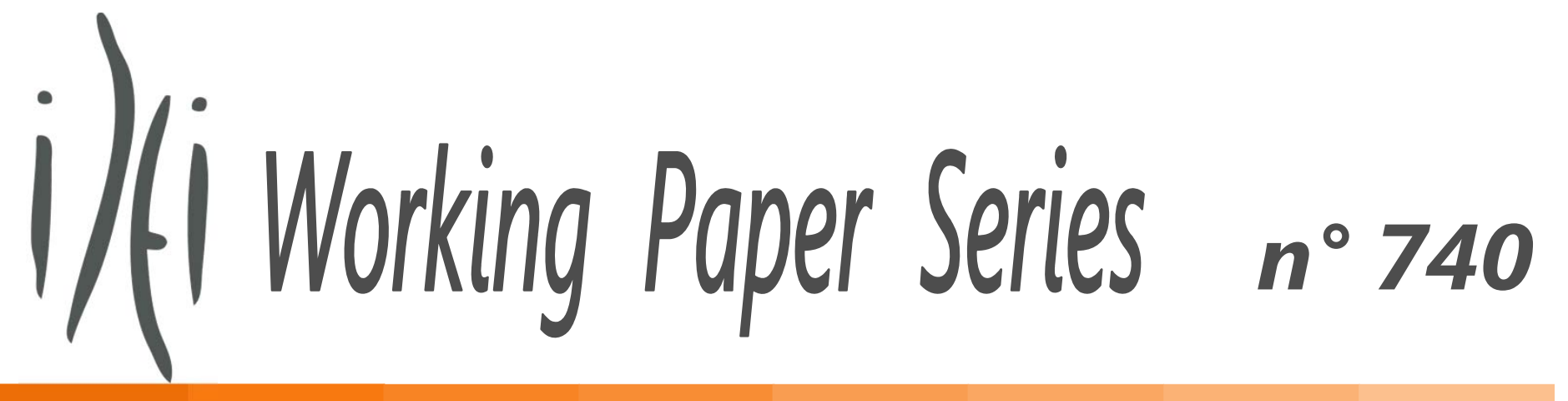

September 2012

\title{
« Liberty and the post-utilitarian society »
}

Gilles Saint-Paul 


\title{
Liberty and the post-utilitarian society
}

Gilles Saint-Paul*

\begin{abstract}
Utilitarian foundations for limited government are shaky insofar as they assume rational and consistent individuals. Recently economists' assumption of rational actors has come under sustained attack. Behavioural economics has suggested that people are plagued by irrational biases and inconsistencies. The author elucidates how these developments have led to a post-utilitarianism which is held to justify paternalistic interventions by the state via 'sin taxes', direct bans or new obligations. Individual responsibility is seriously undermined, as is faith in markets. He concludes that supporters of individual freedom need to move away from utilitarian reasoning, reassert core values of autonomy and responsibility, and define strict limits on the scope of government intervention.
\end{abstract}

JEL classification: B400, D030, D100, H100

Keywords: behavioural economics, utilitarianism, government, paternalism

*Professor of Economics, Toulouse School of Economics 


\section{Introduction}

Government regulation of private behaviour is increasingly accepted. The mayor of New York recently proposed a ban on the serving of super-sized sodas as part of a crusade against the obesity 'crisis'. In the French news, this was presented without even a hint of criticism. An 'expert' was interviewed, and explained to us that this policy was a good idea because it may work. Nobody worried about constitutionally protected freedoms, or asked why a mayor could violate such freedoms at his own discretion.

There are countless examples of such regulations ${ }^{1}$. New ones are introduced every day. Invariably, they are supported by a study which claims that the regulation will have a desirable effect on some key statistical indicator. No other questions asked, in particular questions such as these:

- Why is obesity a "crisis"?

- Why are sodas (which were introduced more than a century ago) responsible for today's obesity, rather than the obese people themselves?

- Why is it the job of the government to curb obesity, in particular by implementing coercive measures which constrain everybody, regardless of whether they are obese?

Traditional liberal thought from Locke to Mill gives simple answers to these questions. There is no reason to object to obesity as long as it is the outcome of conscious personal choice. That some people dislike it is no justification for government intervention that would violate people's natural rights. And finally, overweight people can only blame their own past choices for the adverse consequences that they face, not the availability of sodas and sweets that they could have chosen to avoid.

The unopposed rise of paternalistic policies such as the New York mayor's proposal suggests that we now live in a different paradigm from that of traditional liberals. As I argue at length in my book The tyranny of utility (Saint-Paul 2011), the new paternalistic state finds its intellectual underpinnings in recent developments in economics and other social sciences that provide justifications for far greater government intervention than before.

While economic science traditionally provided support for free individual choice and free markets, this is no longer the case as developments in the new area of behavioural economics undermine the philosophical and theoretical foundations of such support, and instead are used to justify the increasingly intrusive policies that are being implemented today.

\section{Behavioural economics and post-utilitarianism}

\footnotetext{
${ }^{1}$ Many examples are discussed in David Harsanyi's book Nanny State (Harsanyi 2007)
} 
The economist's notion of the common good has historically been grounded in utilitarianism. This means that the welfare of 'society' is defined as the sum of the welfare (also called utility) of its individuals. Why does this view lead to the presumption that individual freedom is desirable? Because economics also assumes that individuals are unitary - that is, made of a single self which is endowed with consistent preferences - and rationally pursue their own interest. Under such an assumption, people choose what is best for themselves among the set of available alternatives: this is called the revealed preference principle. Constraining their choices makes them worse off, and cannot generally improve the welfare of society, since this is the sum of individual welfare, unless somebody else is made better off by a larger amount. This may be the case when we redistribute from rich to poor, since it may be that the increase in the welfare of the poor exceeds the reduction in the welfare of the rich, from society's standpoint. But it cannot be the case if we prevent somebody from drinking a soda, since it reduces his welfare as well as that of the owners of the soda producing firm.

Yet economists now routinely advocate policies that restrict individual behavior, such as 'sin taxes' on smoking, gambling or eating, or the requirement to participate in compulsory savings scheme such as public pensions. Their growing support for paternalism is the consequence of having abandoned utilitarianism. It could be, in principle, that 'society' wants people to be in better health than the individuals themselves appear to do, in which case the government is not maximizing the sum of individual utilities but instead pursuing some higher ideal (not unlike the partisans of eugenics in the not-so-distant past). Economists may remain nominally utilitarian but they are gradually abandoning the conception of the individual as unitary and rational, implying that the revealed preference principle no longer applies. And they do so on the basis of evidence accumulated by psychologists, neuroscientists and others regarding biases in human behavior. These biases come in a variety of forms.

For example, standard theory says that people should use all available information in order to make their best possible inference about the parameters that are relevant for their decisions. But it has been observed that people often process information so as to validate their past choices, that is, they give less weight to, or even ignore, signals which reveal that such choices might have been erroneous. That phenomenon is called cognitive dissonance. ${ }^{2}$ Another form of cognitive dissonance is the 'availability bias', by which people tend to give excessive weight to their own experience. Thus people who were mugged in a particular neighborhood will infer that it is generally a dangerous area, whereas those who were not attacked will believe that this very same neighborhood is quite safe.

Other biases suggest that the individual may be thought of as consisting of multiple selves, rather than a unique and consistent one. Brain scientists have shown that different mental processes conscious and unconscious - compete in order to control the actions of the individual. Some of these processes are 'cognitive', i.e. driven by reason and others 'affective', i.e. driven by emotions and instincts ${ }^{3}$. Therefore, different actions undertaken by the same individual are in fact driven by

\footnotetext{
${ }^{2}$ As an illustration, Lord, Ross, and Lepper (1979) performed an experiment where a group of students is asked to read the same studies about the effects of death penalty. They show that the subjects' prior opinions are reinforced after reading these studies, regardless of whether those opinions were favourable or not.

${ }^{3}$ See Camerer et al. (2005), Berridge (1996) and Ross et al. (1995).
} 
different mental processes. This means they are not mutually consistent and can be interpreted as being chosen by competing selves, or incarnations of the individual.

The 'multiple selves' model may be particularly relevant with respect to the individual's intertemporal choices. If the same individual has different incarnations at different dates, then his $r$ her intertemporal choices will no longer be consistent, and this has important implications for many economic phenomena including savings, incentives, or more generally any transaction or contract involving different dates. Under the phenomenon is called hyperbolic discounting, the present is more 'salient' than the future. For example, I may decide now to save $f 100$ next year, in effect exchanging this sum for, say, $£ 110$ the following year. But when next year arrives I instead consume the $\mathrm{f} 100^{4}$. Thus my choices are inconsistent, as if the person who decides next year were a different incarnation of myself from the one who decides today.

A related theme is that preferences are determined by the context in which the choice has to be exerted. That is, preferences between two alternative choices may depend on the set of third alternatives that are available or on the way the choice problem is formulated, or on both. Furthermore, the well-being derived from an action (say, consuming a good) depends on how that action fares compared to some reference, that is, to what people expect. That reference is itself influenced by the person's past economic experiences, as well as his or her economic environment. For example, numerous empirical studies show that default options matter; that is, more generally, the framing of a decision problem - the way it is formulated - affects which decision is actually made, for a given set of alternatives.

An example of the importance of reference points is the endowment effect. This means that somebody values a good more if he or she already has it. Thaler (1980) and Kahneman, Knetsch, and Thaler (1990) have shown, for example, that people value a good more immediately after they have acquired it. In an experiment, they randomly distributed mugs that were worth $\$ 5$ to their subjects, and then opened a market for those mugs. On average, those who were given the mugs asked for a higher price than those not initially endowed, suggesting that the mere fact of possessing the mugs increased the subjects' utility.

All these biases imply that there is no longer a presumption that people act in their own best interest. Furthermore, if one adopts the view that people are made of multiple selves, the basic decision unit is no longer the individual but a smaller unit: the incarnation. Accordingly, utilitarian social welfare should now be defined as the sum of the welfare of all incarnations, rather than individuals. This is what I label as post-utilitarianism. Furthermore, according to behavioural economics, there is no presumption that different incarnations within the same individual cooperate between them, or, if they do, that the resulting allocation of resources is in agreement with that of a notional 'social planner'. For example, this social planner may constrain the choices of your current incarnation (say by restricting your alcohol consumption or forcing you to save part of your income) in order to increase the welfare of your future incarnation.

\footnotetext{
${ }^{4}$ This psychological phenomenon was uncovered by Chung and Herrnstein (1967). It came back into fashion in economics in particular with the work of Laibson (1997).
} 


\section{The implications of post-utilitarianism}

The transition from utilitarianism to post-utilitarianism eliminates the safeguards against excess government intervention that were associated with utilitarianism. The presumption that individual choices are irrational implies that no area, including privacy, can be left untouched by government intervention. At the same time, public policies and ethics can no longer rely on the notion of individual responsibility. Let us discuss these two implications in turn.

Under traditional utilitarianism, the government does not need to know people's preferences. It can set up a framework which enables mutually profitable transactions to take place, regardless of the actual content of those transactions. If it cares about inequality, it can implement in that framework a mechanism for redistributing money from rich to poor. But again, once this mechanism is in place it does not have to pay attention to how the money is actually spent. Because of the revealed preference principle, much choice can be delegated to the individuals and this is why utilitarianism leads to a presumption in favour of free markets.

In the post-utilitarian society, revealed preferences no longer signify. This means that what is good for the people must be measured directly, and can then be imposed upon them using a wide variety of government interventions, of differing degree of coerciveness.

This involves, for example:

1. The introduction of sin taxes on goods that are considered addictive or dangerous for people with self-control issues, such as alcohol, tobacco, firearms, gambling, sweets, videogames, pornography. There are countless examples of such taxes.

2. Direct prohibition of transactions based on their agreed price or the nature of the good, on the basis that one party cannot possibly rationally benefit from the transaction. For example, a French law bans the rental of rooms smaller than nine square meters, despite that nobody was ever forced to live in such rooms prior to the law ${ }^{5}$. (Needless to say, the media complained about a shortage of student housing in the following year after).

3. Manipulating the way choices are presented to use context effects so as to induce people to make the 'right' choice. Thus post-utilitarians advocate enrolling people into pension funds as a default option, or conspicuously presenting healthy foods ${ }^{6}$. While this has been labelled 'libertarian paternalism' because it does not reduce the set of available alternatives, it is in fact a small tax on the 'wrong' choice (because those who want to make that choice must devote more time and attention in order to overturn the default option), somewhat similar to the Swedish state monopoly on alcohol sales which artificially increases the distance between outlets and reduces their opening hours. In all those examples, we are faced with what is in effect an in-kind sin tax rather than a monetary one.

4. Manipulating beliefs and information so as to induce the correct reaction from the people. This could involve overstating risks and consequences in public campaigns against AIDS or

\footnotetext{
${ }^{5}$ It is not difficult to write formal economic models that support such regulations, see for example Akerlof and Dickens (1982), Sheshinski (2002), Saint-Paul (2002).

${ }^{6}$ See Thaler and Sunstein (2003). These authors' popular work Nudge (Thaler and Sunstein 2008) has apparently been an important influence on UK prime minister David Cameron.
} 
obesity; understating them in order to avoid irrational panic reactions (this what the French government did in 1986 when it denied that the Chenobyl cloud went over the country); undertaking costly actions to accommodate irrational fears. ${ }^{7}$

5. Finally, in a post-utilitarian society there is no presumption of respect for individuals' preferences, since they do not deliver optimal or consistent choices. One can therefore envisage training people to be happy, for example by designing school curricula to that effect, as advocated by some authors ${ }^{8}$.

A very important role is ascribed to the 'experts' who are in charge of measuring the effects of alternative government policies on social welfare. Indeed, as the example at the beginning of this article suggests, we are provided with such expert opinion in the media every time a new policy aimed at restricting individual freedom is put in place. And that freedom carries no weight in the analysis, because the utilitarian and post-utilitarian approaches alike are consequentialist. That is, a given policy is evaluated on the basis of its final effect on the material allocation of resources alone, irrespective of whether or not the process by which such allocation is attained is acceptable. Once the experts ${ }^{9}$ have provided evidence that the policy improves social welfare, it can be implemented without any further discussion. In particular, no attention is paid to the fact that the policy affects individuals differently. For example, banning sodas may prevent compulsive drinkers from gaining weight, but how about reasonable drinkers who have no particular weight problems, and whose set of choices is being coercively restricted? This argument does not matter to the paternalists, not only because they are consequentialists, but also because as post-utilitarians, they only care about total welfare and disregard individual cases ${ }^{10}$. As long as we believe that on average the policy works (say we have proved that the average weight of New Yorkers will fall if sodas are banned), it will be considered as beneficial. This in turn means that it is enough to measure the average effect of the policy, and to conduct the whole discussion in terms of averages.

Yet even from a post-utilitarian perspective, it would seem more efficient to let people without weight problems consume what they want, and to impose restrictions on overweight people only. For example why not impose higher taxes on them, thus giving them incentives to become slimmer? This would presumably be more efficient than a tax or a ban on sodas, since under such a scheme all sources of excess weights are taxed equally. One may object that this may run into a concern for equality. Maybe, but any crusade against obesity will inevitably impose higher costs on those people who are prone to eat more, so one may argue that such policies are inherently inegalitarian. Another objection is that this would be unpractical as it would involve obtaining a measure of weight in order to determine one's income tax. However this is no different from many other items involved in a tax return, for which tax authorities collect informations on the basis of voluntary reporting subject to checks and penalties. The real reason why taxing weight directly is not contemplated, is that the post-utilitarian paradigm considers that such incentive schemes, and more generally policies that rely on individual responsibility, are inefficient and lack a moral justification.

It only makes sense to hold individuals responsible for the consequences of their actions if they are considered as unitary. If instead we consider them as consisting of multiple selves it follows that the

\footnotetext{
${ }^{7}$ See Salanié and Treich (2007).

${ }^{8}$ See Layard (2007).

${ }^{9}$ Such experts, of course, may themselves be subject to biases though this possibility is frequently ignored.

${ }^{10}$ This is also true, of course, of utilitarianism.
} 
incarnation that bears the consequences of one action may differ from the one which chose that action. Thus if individuals suffer from the consequences of their past choices we consider them as victims of their past incarnations as if those were different individuals, who cannot be penalized since they no longer exist.

In a post-utilitarian world it is no longer morally justified to impose negative penalties on people because of their past choices. And by the same token, relying on traditional reward and penalty structures may be inefficient, as the incentives elicited by these structures are weakened by the fact that the incarnation being punished/rewarded will be different from the one undertaking the action. Thus, it is difficult to deter Mr Hyde from committing a crime if he believes that Dr Jekyll, rather than himself, will suffer from the subsequent sentence.

From this perspective it is not surprising that our societies increasingly rely on prevention rather than penalties. The emphasis on prevention again opens the door for limitless government infringement on personal freedoms. In the traditional liberal society, only those actions that directly harm other people, such as murder, violence and theft, are supposed to be penalized. In the post-utilitarian society, where people are not deemed to be capable of self-control, any action which may initiate a chain of events whose final consequences are harmful may be legitimately restricted. Since the incarnation, rather than the individual, is now the basic unit of welfare analysis, the logic applies regardless of whether the harm being done at the end of the chain of events is to individuals themselves or to third parties.

Thus cigarette candies have been banned in France, because they might induce children to smoke at a later age (although neither cigarettes nor candies are banned). New York City's mayor wants to ban supersize soda, because some people may drink too much of it and become overweight. These preventing measures are meant to protect people against themselves. Other examples, such as a law preventing bartenders in France from serving alcohol to clients who may be intoxicated, against the client's will and against their own commercial interest, are supposed to prevent harms to third parties, for example in a road accident.

At the same time that more preventive measures are being introduced, and for the same reason, we see more reluctance to let people bear the consequences of their own choices. This explains why we see unconditional social assistance coupled with compulsory contributions to pension systems; free medical treatment for diseases caused by lifestyles coupled with taxes on tobacco, Scotland's minimum prices for alcohol and Denmark's tax on foods containing saturated fat; free availability of methadone and needles to addicts, while consumption is illegal for non-addicts.

But replacing repression with prevention involves a contradiction. In order to enforce prevention, the government must pass new laws that make some previously legal actions now illegal. But to enforce those laws it must implement sanctions for those who break them. Therefore we cannot do away with repression. But, if the preventive law was passed on the grounds that repression does not work, how can that law be enforced? The answer to this contradiction is to selectively apply repressive tools to responsible individuals and organizations alone. Furthermore, it is also efficient for a postutilitarian state to endow these responsible entities with the task of enforcing preventive measures to constrain the behaviour of irresponsible people, whenever that is feasible. Thus, in the above example, the irresponsible drinker cannot be trusted and the bartender is asked to internalize social welfare by refusing to serve his or her client. This is the phenomenon of responsibility transfer. 
In some sense, responsibility transfer is a new socialism of rationality. As in a Marxist society where one gives to each according to his needs and asks from each according to his abilities, in a world where responsibility transfer is pervasive, those who are considered to be rational bear the burden of responsibility. Incentives and penalties only apply to them, while the others are treated as legal and moral minors. As in the bartender and other examples, penalties for their harmful actions are transferred to the responsible caste to the extent that their interactions with them can be considered as a cause of the harmful action. And, as in a Marxist society where there is no incentive to create wealth, perverse effects arise. People may voluntarily put themselves in situations where they are exempted from individual responsibility, while the responsible ones may refrain from interacting with the irresponsible caste ${ }^{11}$.

Another area open to greater regulation because of paternalistic concerns is that of markets. Markets are the enemy of paternalists for at least three reasons. First, there is no longer a presumption that they will clear efficiently, because the agents who perform arbitrage are no longer seen to do so rationally, but are instead influenced by behavioural biases such as overconfidence or compulsive trading. Therefore, there is no longer a presumption that markets deliver the correct price. Second, sellers may exploit the buyers' biases, for example by using teaser rates or various forms of manipulative advertising, in order to induce them to make purchases against their own interest. Third, markets may allow people to undo the paternalistic policies that are imposed upon them. Banning supersize sodas will have no effect if one can buy two regular sodas instead. Compulsory savings schemes can be undone by borrowing against the future returns from such schemes. Being banned from casinos, even voluntarily, cannot be enforced if new casinos constantly enter the market or if online betting sites proliferate.

\section{Conclusion}

For those of us who believe that individual freedom and limited government are important cornerstones of our society, is there some way one can resist the rise of the paternalistic state?

It would be tempting to restore the old utilitarian foundations for limited government by denying the relevance of behavioural biases. Yet these biases are well documented by recent research, and if anything the attacks against individual freedom that we observe tell us how shaky these utilitarian foundations really were ${ }^{12}$.

Surely the reason why we care about individual rights goes beyond the hypothesis that they are an efficient tool to decentralize the allocation of resources? It is therefore necessary to move beyond utilitarianism and restore individual autonomy, freedom and responsibility as core values of our society, and accordingly define strict limits on the scope of government interventions. This involves

\footnotetext{
${ }^{11}$ There are countless examples of regulations that backlash against the very people they are supposed to protect. For example, in France, it is very difficult to expel a tenant for nonpayment of the rent if he or she is unemployed or old. As a result, elderly people or people with precarious jobs have considerable difficulties renting a home.

${ }^{12}$ Note however that post-utilitarian arguments against paternalism can be made, by noting that politicians and bureaucrats themselves are prone to behavioural biases. See Glaeser (2005).
} 
living with the consequences and getting rid of the idea that the government is a benevolent tutor in charge of general happiness. At present, unfortunately, few forces seem to oppose the rise of paternalism.

\section{References}

Akerlof, George A., and William T. Dickens. 1982. "The Economic Consequences of Cognitive Dissonance." American Economic Review 72, no. 3: 307-319.

Berridge, Kent C. 1996. "Food Reward: Brain Substrates of Wanting and Liking." Neuroscience and Biobehavioral Reviews 20, no. 1: 1-25.

Camerer, Colin, George Loewenstein, and Drazen Prelec. 2005. "Neuroeconomics: How Neuroscience Can Inform Economics." Journal of Economic Literature 43, 9-64

Chung, S. H., and Herrnstein, R. J. 1967. "Choice and Delay of Reinforcement." Journal of the Experimental Analysis of Behavior 10:67<n->64.

Glaeser, Edward. 2005. "Paternalism and Psychology," Harvard Institute of Economic Research Discussion Paper

Harsanyi, David. 2007. Nanny State. New York: Broadway Books.

Kahneman, Daniel, Jack Knetsch, and Richard Thaler. 1990. "Experimental Tests of the Endowment Effect and the Coase Theorem." Journal of Political Economy 98, no. 6: 1325<n->1348.

Laibson, David. 1997. "Golden Eggs and Hyperbolic Discounting." Quarterly Journal of Economics 112, no. 2: $443<n->477$. 
Layard, Richard, 2007, 2007. "Happiness and the Teaching of Values." CentrePiece (summer): $18<n-$ $>23$.

Lord, Charles G., Lee Ross, and Mark R. Lepper. 1979. "Biased Assimilation and Attitude Polarization: The Effects of Prior Theories on Subsequently Considered Evidence," Journal of Personality and Social Psychology 37, no. 11: 2098<n->2109.

Ross, Lee, Mark R. Leppner, and Michael Hubbard. 1995. "Perseverance in Self-Perception and Social Perception : Biased Attributional Processes in the Debriefing Paradigm." Journal of Personality and Social Psychology 32, no. 5: 880<n->892.

Saint-Paul, Gilles. 2002. "Cognitive Ability and Paternalism." Centre for Economic Policy Research Working Paper \{AU: PLEASE PROVIDE NO.\}.

Saint-Paul, Gilles, 2011, The tyranny of utility. Princeton: Princeton University Press

Salanié, François, and Nicolas Treich. 2007. "Regulation in Happyville.” Economic Journal

Sheshinski, Eytan. 2002. "Bounded Rationality and Socially Optimal Limits on Choice in a SelfSelection Model." Hebrew University Working Paper No. \{AU: NO.?\}.

Thaler, Richard H. "Toward a Positive Theory of Consumer Choice." Journal of Economic Behavior and Organization 1, no. 1: 39<n->60.

Thaler, Richard H., and Cass R. Sunstein. 2003 "Libertarian Paternalism." American Economic Review 93, no. $2: 175<n->179$.

Thaler, Richard H. and Cass R. Sunstein 2008 Nudge: Improving Decisions about Health Wealth and Happiness Yale UP: New Haven 